\title{
Incentives toward conservation of argali Ovis ammon: a case study of trophy hunting in western China
}

\author{
Richard B. Harris and Daniel H. Pletscher
}

\begin{abstract}
We investigated management of wildlife, habitat and the hunting programme in Aksai County, Gansu Province, People's Republic of China, during 1997-2000. Argali Ovis ammon is the focal species both for conservation and hunting. The hunting programme is intended to produce incentives to conserve wildlife and habitat. Poaching, a serious concern throughout western China, has been reduced in recent years in Aksai. Wildlife population trends are unknown because standardized surveys were begun only in 2000. Threats to argali in Aksai include livestock grazing, placer gold mining, and development of a dam, reservoir and aqueduct. The number of hunters participating in the programme (c. 3 per year) could provide considerable funding (c. $\$ 60,000$ per year), but the allocation of these funds within China has provided too little for conser-
\end{abstract}

vation at the local level, thus undermining the intended incentive system. Because local wildlife protection officials have been denied both funding and authority to deal with threats to the wildlife, the programme's contribution to conservation has been minor. We recommend that hunters pay fees directly to county-level staff, thus increasing the proportion of funds retained at countylevel, and that this added income is used to obtain wildlife grazing rights on important seasonal habitats for argali. These changes would promote local wildlife conservation without the need for additional external funding.

Keywords Aksai County, argali, China, conservation incentives, Ovis ammon, trophy hunting.

\section{Introduction}

Sustainable use as a means to conserve vulnerable wildlife resources relies on 'use' creating incentives toward 'sustainability' (Freese, 1997, 1998). Conservation is achieved, despite the deliberate loss of individuals, because the population and its required habitat must be protected adequately to allow indefinite persistence of both. Hunting of highly valued species is one example of sustainable use (Swanson, 1992). Southern African countries have the most experience of this, offering expensive hunts to foreign hunters (Metcalf, 1994; Lewis \& Alpert, 1997). Sustainable hunting has also been suggested for certain highly valued ungulates of Western China (Cai et al., 1989; Stiver, 1989; Harris, 1993), and was adopted by Chinese authorities in the late 1980s.

Some people argue that trophy hunting does little to help wildlife populations, and instead provides avenues for business transactions between wealthy foreign hunters and cash-strapped government bureaux (Cunha, 1997; Schaller, 1998). Others argue that such programmes are

Richard B. Harris (Corresponding author) and Daniel H. Pletscher Wildlife Biology Program, University of Montana, 218 Evans, Missoula, Montana 59801, USA. E-mail: rharris@montana.com

Received 20 September 2001. Revision requested 5 March 2002. Accepted 28 May 2002 detrimental, increasing the threat to the animal populations (Wade, 1992; PEER, 1996).

We assessed the status of the Kharteng International Hunting Area (KIHA), focusing on argali Ovis ammon in Aksai Kazak People's Autonomous County, Gansu Province, China. Foreign hunters can legally purchase permits to kill argali, blue sheep Pseudois nayaur, Tibetan gazelle Procapra picticaudata and goitered gazelle Gazella subgutturosa, although the other species are considered less valuable than argali by hunters and are priced lower by Chinese authorities. Nationwide hunting quotas for argali are established by the Office of Wild Fauna and Flora Protection of the State Forestry Administration in Beijing, in consultation with the Endangered Species Scientific Commission of China (Jiang, 2000). Quotas are applied to entire provinces, rather than to management areas or population units (Jiang, 2000). Argali quotas for Gansu during 1997-99 were 15, 15 and eight, respectively (Jiang, 2000), divided among the three hunting areas within Gansu (KIHA, Subei Hashiha'er and Subei Mazongshan).

Argali are the largest of wild sheep, and the impressive horns of adult males and the difficulty of approaching these wary and secretive animals makes them particularly prized by trophy hunters (Stiver, 1989; Harris, 1995). However, argali are rare and vulnerable to numerous human-related threats. O. ammon is categorized as Vulnerable on the 2000 IUCN Red List (Hilton-Taylor, 
2000), with subspecies variously categorized as Critically Endangered, Endangered or Vulnerable, and is also listed in Appendix II of CITES (except for O. a. hodgsoni in China and O. a. nigrimontana of Kazakstan, which are listed in Appendix I). All Chinese argali are listed as Endangered under the United States Endangered Species Act. The aim of our work was to assess whether trophy hunting for argali is sustainable, and how fees from hunting could best be used to improve the conservation of this species.

\section{Study Area}

Aksai Kazak Autonomous County was created from portions of Gansu, Qinghai, and Xinjiang Provinces in 1953. The county is one of China's largest in area (c. $33,500 \mathrm{~km}^{2}$, almost entirely desert and mountain grasslands), but smallest in population (1993 census of 7,229, of which roughly half were ethnic Kazaks; Yang, 1993).

KIHA (Fig. 1), established in 1988 (Gansu Forestry Bureau, 1990), is administered by the Aksai County
Wildlife Protection Station (AWPS), and is within Jianshe Township (c. 13,850 km²), one of Aksai County's four townships. Jianshe's total human population was 1,037 in 1990 (Yang, 1993), but we estimate that it was approximately half that by 1999. Elevations vary from 3,100 m on the Kharteng River to 5,668 m in the Danghe Nanshan range. Livestock raising (primarily sheep and goats, secondarily horses and camels) is currently the principal economic activity in and near KIHA. Livestock range seasonally over elevations of 3,500-4,200 m. Vegetation is the Stipa purpurea formation (Zhou, 1990), with scrub desert in the lower elevations and generally bare rock above $4,600 \mathrm{~m}$.

\section{Methods}

We conducted a preliminary survey of argali distribution and initial interviews with Aksai staff during August 1997. While attempting to capture argali for radiomarking, we conducted additional informal surveys and

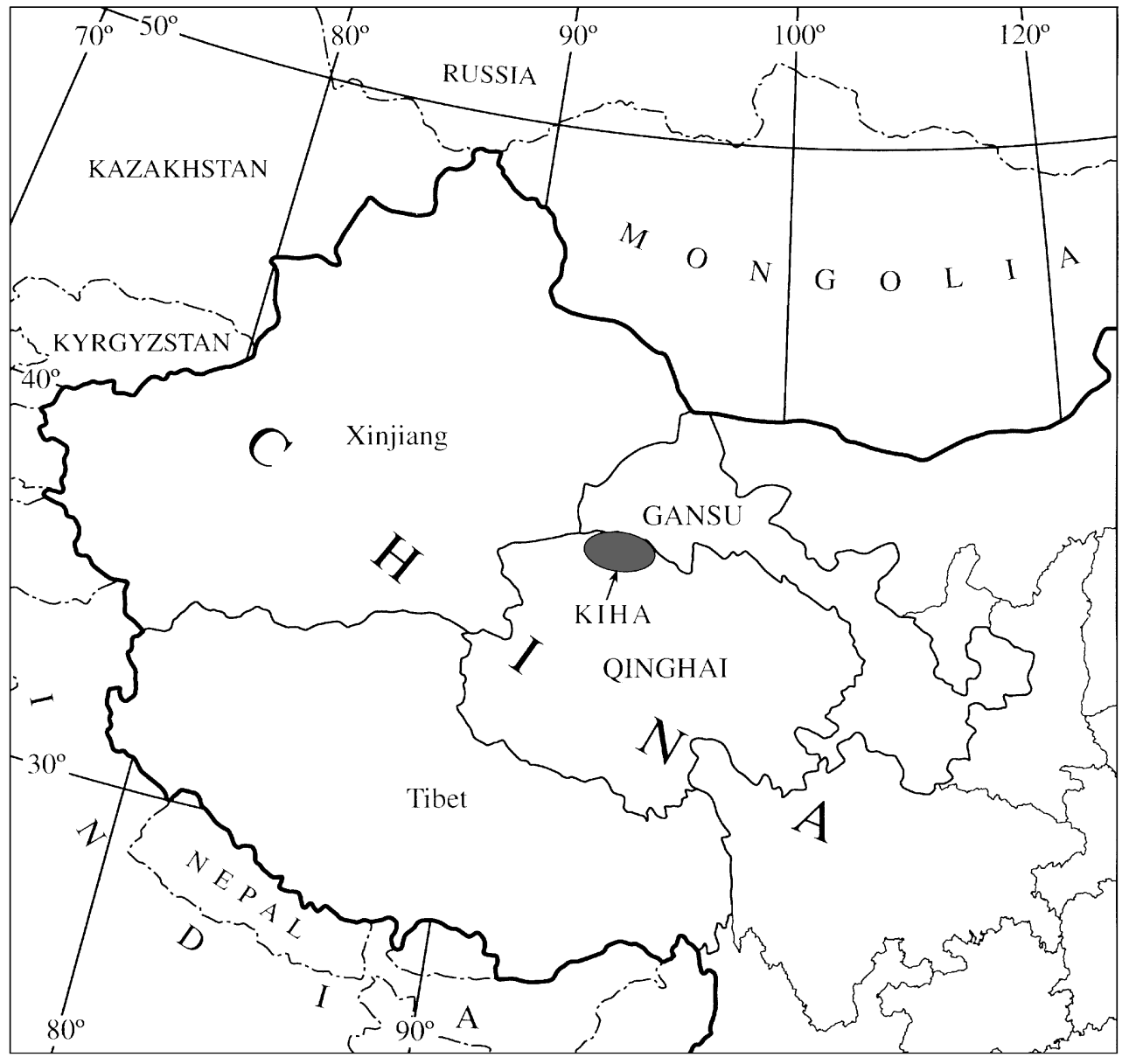

Fig. 1 Location of the Kharteng International Hunting Area (KIHA), Aksai County, Gansu Province, China. Although administered by Gansu, KIHA is located within Qinghai Province as displayed on most maps. 
interviews during October-December 1998, and AprilMay 1999. From 17 September to 5 October 2000 we estimated the number of argali within KIHA by scanning all areas likely to be used by argali. We travelled through as much habitat as possible by vehicle and ascended to ridges or peaks by foot to scan visible areas, using binoculars and telescopes. When we observed an argali group, we determined our own position using a Global Positioning System, mapped the approximate position of the group on 1:50,000 topographic maps, and judged observations as duplicates of previously counted animals based on distance from other observations and group composition (Harris et al., 2001).

During August 2-13 2000, we used a rapid rangeland reconnaissance method to qualitatively estimate pasture conditions (Harris \& Bedunah, 2001). We conducted open-ended interviews with livestock herders to determine their opinions on land conditions, long-term changes in grazing and wildlife numbers, and historic patterns of livestock management. We selected herders that were based near the areas where we conducted range reconnaissance, although we also interviewed herders that were known to have the longest history of tenure in KIHA. We conducted the interviews outside, as the herder was tending his or her herd, or in the herder's tent. We asked questions about herd structure, movement of livestock, condition and desirability of spring and winter camps, livestock products, marketing of livestock and livestock products, risk management, water resource use, length of time herding, depredation of livestock by wild predators, cooperation with other herders, and grazing management concerns.

We obtained information on administration, finances, and management of the hunting area from unpublished documents and informal interviews with AWPS staff (Harris \& Pletscher, 1997; Harris, 1999). We used data collected by AWPS staff on age and size of rams killed to examine trends over time. We tested the null hypotheses that there was no effect of time on age and horn length of rams killed using least-squares linear regression. We also discussed our observations and views with AWPS staff, and benefited from their insights. Open-ended interviews and discussions with local staff and officials were conducted in Chinese by $\mathrm{RBH}$; some interviews with pastoralists were translated into Chinese from Kazak. The exchange rate was approximately Chinese $¥ 8.2$ = USA $\$ 1$ during the study period.

\section{Results}

During surveys in 2000 we documented at least 255 argali in KIHA, and speculate that perhaps up to 300 were present (Harris et al., 2001). Most of the pastoralists that we interviewed held the opinion that the argali population was either stable or had increased, although their point of reference for these views was usually unclear.

Hunting quotas for argali were developed without advice from field staff in Aksai or Gansu provincial administrators, and the rationale and methodology for developing the quotas were not published. From 1990 to 2000, 33 argali rams were killed in KIHA (Fig. 2). During this time only one argali hunter was unsuccessful. Fifteen blue sheep and 16 gazelles (all males) were also legally killed during this period, although hunter success rate was not documented because the intention and effort of hunters to take these species was often variable and unclear.

The international hunters originated from Andorra (1), Austria (2), Canada (2), Denmark (2), France (2), Germany (2), Italy (1), Mexico (5), Spain (3), Switzerland (1), and USA (6). All the argali killed by hunters in KIHA were male, and no losses from wounding were reported during 1998-2000 (information on possible wounding was unavailable for earlier years). The mean age (as estimated by AWPS staff from horn annuli) of rams killed was 8.2 years $(\mathrm{SE}=0.2, n=33)$. The age of males killed did not change significantly with time ( $F=1.93, \mathrm{df}=1,31, P=0.17$; Fig. $3 a)$. The average length of the longest horn of rams killed by hunters was $110.6 \mathrm{~cm}(\mathrm{SE}=1.4)$, with no detectable change through the time period $(F=0.02, \mathrm{df}=1,31, P=0.90$; Fig. $3 b)$.

Prior to 1997, AWPS staff produced c. 10 public information notices (in both Chinese and Kazak) to publicize laws against poaching. These notices, painted on wearresistant stone, were placed in strategic locations along the primitive road system in and around KIHA. By 2000 most of the notices required repainting and maintenance. AWPS staff also conducted informal educational sessions with local pastoralists. No patrols were made to specifically deter or apprehend poachers, and AWPS staff spent little time in the field other than that associated with preparing and conducting hunts.

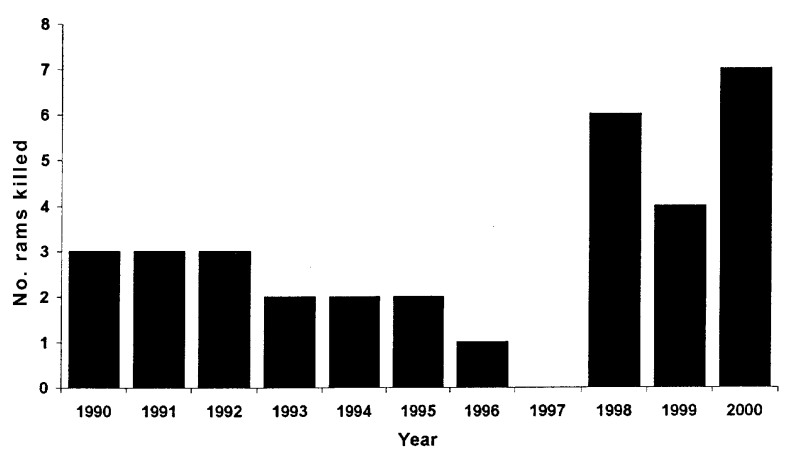

Fig. 2 Number of argali rams taken each year at the Kharteng International Hunting Area, 1990-2000. 

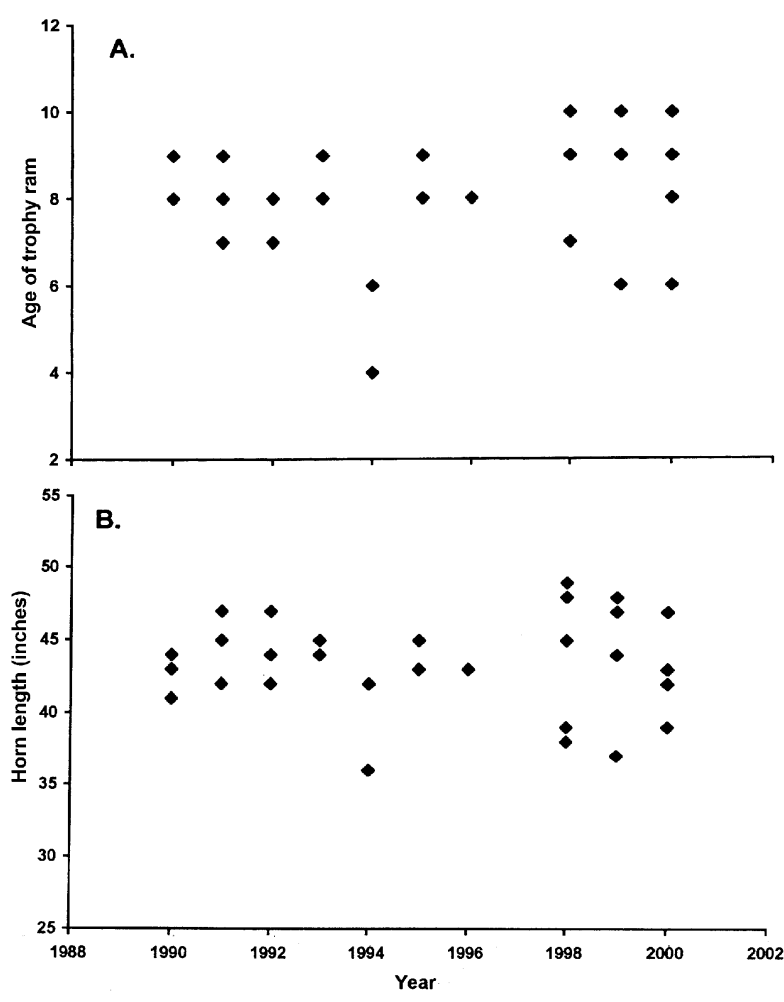

Fig. 3 (a) Age and (b) length of horns of male argali killed by hunters at the Kharteng International Hunting Area, 1990-2000. Some of the data points represent more than one individual.

Neither AWPS staff nor we documented any poaching incidents involving argali during 1997-2000, and we believe that subsistence argali poaching had been reduced to inconsequential levels by the late 1990s. In December 1998, however, government officials from neighbouring Subei County killed approximately 20 wild yaks Bos grunniens and several Tibetan gazelles, and evidently intended to sell the meat in nearby Dunhuang. The offenders were apprehended with the assistance of AWPS staff and were subsequently tried, convicted and imprisoned.

Approximately 50,000 domestic sheep and goats, and 2,000-4,000 horses and camels grazed in Jianshe Township, potentially affecting argali habitat. Intensity and patterns of livestock grazing substantially limited the argali population through competition for similar plant food species and temporal and spatial displacement (Harris \& Bedunah, 2001). During winter and spring when forage options were limited, argali and domestic sheep and goats in close proximity subsisted on similar plant species (Morisita index of overlap $C_{\lambda}=0.98 ; 1.00$ is perfect dietary overlap, see Horn, 1966). Domestic herds appeared to displace argali from areas that provided an optimum combination of forage availability and quality, and predator avoidance (Harris \&
Bedunah, 2001). The number of horses, which have a disproportionate impact on vegetation and soils, was much higher than the number required for transportation (Harris \& Bedunah, 2001).

Itinerant placer gold miners, mostly from eastern Qinghai province, were present within KIHA during our survey and, according to interviewees, this has been true for over a decade. Where placer mining had taken place, vegetation was usually lost entirely. In areas where vegetation had regrown we observed an absence of palatable grasses, such as species of Stipa and Poa, and a dominance by unpalatable, and occasionally poisonous, species such as Clematis tangutica and C. florida. Until 1999, placer miners were generally small groups (10-30) of entrepreneurs, working independently. In August 2000 we counted 12 large dredge boats in the Kharteng river upstream from KIHA, and were told that approximately 200 people were camped nearby in connection with this commercial operation.

Hydrologists from Dunhuang, camped on the Kharteng River during the summers of 1999-2000 and documenting the river's flow rate, told us of plans to build a dam near this location, impounding the Kharteng River. The plans include construction of an aqueduct and numerous pumping stations to move water from the river to adjacent Subei and Dunhuang Counties, where it would be used for agriculture.

During 1998-2000, argali hunters were charged US $\$ 12,000$ per hunt $(\$ 10,000$ per person per hunt if two or more people hunted together), plus a trophy fee of $\$ 9,500$ if successful (i.e. $\$ 21,500$ or $\$ 19,500$ per trophy; CWCA, 1998). Blue sheep could be added for $\$ 2,500$ each and gazelle for $\$ 1,200$. An additional $\$ 500$ was charged for domestic airfare and accommodation, \$500 per day beyond 8 days, and $\$ 900$ for each non-hunting accompanying person and an additional $\$ 180$ per day if the hunt required more than 5 days (CWCA, 1998).

During 1998-2000 all hunters used foreign booking agents as intermediaries. As most overseas booking agents retained a $15-20 \%$ commission, the funds reaching China were $80-85 \%$ of the published prices. The official in-country breakdown of funds from international hunters was $20 \%$ to the federal level, $30 \%$ to the provincial level, $5 \%$ to the prefecture level, and $45 \%$ to the county level (Harris, 1995; Liu, 1995). Unofficially, 16\% was first deducted at the national level for support of the Import/Export and CITES offices. Thus, proceeds to the county level were $32 \%(=0.85 \times 0.84 \times 0.45 \times 100 \%)$ of that paid by the hunter.

At the county level $50 \%$ of funds was retained for general expenditure by the county treasury and the remainder was provided directly to wildlife protection stations. Thus, c. $16 \%$ of the fees paid by hunters were available to the AWPS, from which field expenses for 
hunts were also paid (salaries and overheads of the wildlife stations were paid by the county treasury). Based on the costs of our own fieldwork and information provided by AWPS staff, we estimated field expenses at c. $\$ 2,400$ per hunt, which is approximately equal to $16 \%$ of the hunters' fees. Thus, under this funding scheme, AWPS receive only enough to cover hunting services (Table 1).

Beginning in 1998 Aksai County altered this arrangement, and began allowing AWPS to keep all countylevel funds. At this time, however, the county ceased supporting AWPS, and began treating it as a private enterprise, although it remained officially a government bureau. Salaries and overheads become the responsibility of AWPS (i.e. paid entirely by hunters' fees), and taxes were also levied on its income and property. This partial privatisation produced little change in total funding available to AWPS, but increased their dependence on a steady supply of overseas hunters.

No provision existed for funds to be channelled to government levels below the county (e.g. township level). Monetary benefits to pastoralists living where hunts occurred were limited to horse rental provided by four pastoral families with seasonal pastures nearest to the preferred hunting areas. Thus there were no direct financial benefits to the majority of people whose family economies were potentially affected by the presence of wildlife.

Hunters remitted funds only to the in-country agents at the national level, who then transferred them to the provincial level. We were not permitted to see details of accounting but, according to AWPS staff, payments to Aksai County during 1998-2000 were late and incomplete. As of August 2001 the AWPS had received only about half of the funds due it from hunts that occurred during 1998-2000 (i.e. c. 8\% of monies expended by hunters). As a result, during 1999 AWPS went into debt by approximately $¥ 20,000$ and was forced to take out a loan from the county government to continue operations. By October 2000, AWPS staff informed us that their budget had become sufficiently stressed that payment of their salaries had been delayed pending receipt of funds owed to them for hunts conducted during 1998-2000. We have no reason to suspect AWPS of wasting money or spending inappropriately, and believe the shortfall came entirely from failure of higher government levels to transfer funds due.

\section{Discussion}

Although Liu et al. (2000) published a figure of 0.431 argali $\mathrm{km}^{-2}$ for KIHA, neither source, methods, area surveyed, nor time period for this estimate were provided. Thus, there were no quantitative surveys from which to infer recent trends in the argali population in and around KIHA. We believe, however, that before the establishment of trophy hunting the argali population was below the carrying capacity of the habitat because of the history of subsistence poaching. Upon arrival in the Kharteng area in the 1930s, Kazak herders had few livestock, and supplemented their diet with wild game

Table 1 Approximate allocation of foreign hunter fees per argali trophy to each administrative level of the Gansu argali hunting programme in 1997-98, according to local officials. Hunters participating in groups were charged $\$ 19,500$ each (rather than $\$ 21,500$ illustrated here). All figures are US\$. As noted in text, funds actually reaching Aksai County during 1998-2000 were approximately half of these expected figures.

\begin{tabular}{|c|c|c|c|}
\hline Percentage & Funds allocated & Use & Funds remaining for lower level \\
\hline & & & 21,500 \\
\hline \multicolumn{4}{|l|}{ Level I } \\
\hline \multirow[t]{2}{*}{$15 \%$ of 21,500} & 3,225 & Foreign booking (Commission) & \\
\hline & & & 18,275 \\
\hline \multicolumn{4}{|l|}{ Level II } \\
\hline \multirow[t]{2}{*}{$16 \%$ of 18,275} & 2,924 & CITES, Export/Import (Admin.) & \\
\hline & & & 15,351 \\
\hline \multicolumn{4}{|l|}{ Level III } \\
\hline $20 \%$ of 15,351 & 3,070 & National level (Admin.) & \\
\hline $30 \%$ of 15,351 & 4,605 & Provincial level (Admin.) & \\
\hline $5 \%$ of 15,351 & 768 & Prefecture level (Admin.) & 6,908 \\
\hline \multicolumn{4}{|l|}{ Level IV } \\
\hline \multirow[t]{2}{*}{$50 \%$ of 6,908} & 3,454 & General county funds & \\
\hline & & & 3,454 \\
\hline \multicolumn{4}{|l|}{ Level $V$} \\
\hline \multirow[t]{2}{*}{$74 \%$ of 3,454} & 2,400 & AWPS hunt expenses & \\
\hline & & & 1,054 \\
\hline \multicolumn{4}{|l|}{ Level VI } \\
\hline & 1,054 & Conservation purposes & \\
\hline
\end{tabular}


(Aksai County, 1985). Major reductions to all populations of large wild mammals in the Kharteng area occurred over 1959-62 during the widespread famine associated with the Great Leap Forward, when governmentsupported pastoralists and army troops killed wildlife both for themselves and the market place. Provincial records show that 385 wild ass Equus kiang and 300 wild yak were killed in Aksai county in 1959 alone (Gansu Forestry Bureau, 1990); given the popularity of their meat, argali were probably also heavily hunted at this time. Most local pastoralists thought argali have now increased compared to previous levels, but we were generally unable to determine the reference point from which the pastoralists made this assessment; thus, some may have used the low numbers of the early 1960s as a reference point.

Male argali killed by hunters have tended to be relatively old, and the age of the rams taken did not decrease over time, suggesting that the harvest rate was not excessive. Caveats to concluding from these data that the harvest has been sustainable are: (1) determination of argali age from horn annuli counts is imprecise, particularly among older age classes; (2) lack of a trend in a closed population is suggestive of stability, but the locations from which the rams were taken has varied, leaving the possibility that older rams from one portion of the argali range were depleted, and rams taken later represented expanding hunting pressure; (3) the distribution of size and age of rams taken depends on the skill of the hunters in killing the individual rams suggested by AWPS hunting guides (in some cases the rams that were taken were not the largest available); (4) cohort effects can potentially mask relationships between age at harvest and population trend (Carey \& Dehn, 1998). Nevertheless, these data tend to support the conclusions of Harris et al. (2001) that trophy harvests of five or fewer per year are unlikely to cause local population declines or to disrupt normal breeding behaviour.

Poaching is usually considered to be the greatest threat to argali populations in Western China (Schaller, 1998). Some of the success in reducing poaching in KIHA can be attributed to efforts of AWPS staff and the presence of the hunting programme, but three other factors have also tended to reduce poaching of argali in Aksai County, independent of enforcement from AWPS staff: (1) Argali were displaced seasonally by migratory domestic sheep herds (Harris \& Bedunah, 2001), and thus pastoralists rarely had easy access to argali because of the disturbance created by their own activities; (2) poaching by local residents was made virtually impossible in 1998 when all guns were confiscated county-wide by public security officials, prompted by an incident of violence and not by concerns about poaching; (3) in recent years most commercial poaching in Western China has focused on Tibetan antelope Pantholops hodgsoni because of the large profits available from smuggling antelope wool (shatoosh).

Although the presence of poachers in western Qinghai, eastern Xinjiang, and northern Tibet probably puts other species at risk as well, Tibetan antelope have not historically extended north of the Qaidam Basin into the Kharteng area (Schaller, 1998; Harris et al., 2001), and thus commercial poachers, most of whom live in eastern Qinghai, have not had reason to operate in KIHA or elsewhere in Aksai. Poaching by gold miners is always a threat because they are often armed and usually camp in remote locations. In addition, their mining activities result in extensive and substantial damage to the stream beds and riparian areas in which they work. These areas have a disproportionate importance for both wildlife and livestock because they support more diverse and productive plant communities than do the adjacent slopes. Itinerant gold miners are generally disliked by local people in Aksai, but the County officially welcomes them because the county government obtains funds from a strategically located tax station.

It is unlikely that the amount of available plant material is limiting for argali, but the animals probably have difficulty obtaining combinations that produce optimal mixtures of energy and protein (Hobbs \& Swift, 1985) because of the high levels of domestic grazing. We believe it likely that displacement from preferred habitats caused by the movements of domestic sheep herds also negatively affected survival or recruitment of argali.

Grazing lands within KIHA are all under long-term contract to family units herding livestock (Harris \& Bedunah, 2001). Although these lands formally belong to the government, they are not subject to any specific land-use regulations. The livestock industry in this part of China operates on a private-property mimicking basis and, except for requiring seasonal movements of domestic herds and levying taxes, government authority does not extend to specific control of management activities on these lands.

The planned reservoir within KIHA would inundate habitat that was preferred by, and may be critical for, argali during winter and spring (Harris \& Bedunah, 2001). We do not know whether it would obstruct movements that currently take place between summer/ autumn argali habitats north and south of the river. Regardless, the potential for considerable disturbance and poaching caused by the rapid influx of thousands of workers (together with the necessary infrastructure to support them in this remote area where there are presently only a handful of migratory pastoralists) is obviously high. 
Hunting programmes can be categorized either as essentially wildlife conservation programmes, in which funds from hunters are used to partially or entirely offset the running costs, or as essentially business enterprises, where an otherwise rare species exists locally in sufficient abundance to justify generation of employment and profits. The two differ in fundamental objectives and incentive structures, and thus in the type of support merited from the international conservation community. In conservation-based hunting programmes the local staff are wildlife managers who also offer hunting services, whereas in business-based programmes the local staff are travel agents and guides who hope that, by engaging in business activities, wildlife will automatically be well managed.

KIHA is primarily a business enterprise, rather than a wildlife conservation programme, because most power and benefits are held at the national level, and those with the most ability to manage the populations and habitat (AWPS) are provided with few tools and funds. Because benefits and responsibilities are inverted, the link between business success and conservation success is weak and conservation is not assured.

Current policy looks towards market forces to assist in conservation, and AWPS is treated and expected to operate like a profit-making business. AWPS will prosper if it succeeds in its fundamental objective of providing high-quality hunts. This, in turn, necessitates conservation of the argali population within KIHA. The hoped-for incentive structure links success of the quasi-business enterprise directly to the health of the population that is hunted.

This approach is reasonable, given the existing political, economic, and historical constraints, but is flawed because AWPS is controlled and limited by higher government authorities in ways that would not apply to a business enterprise operating in a free-market economy. Firstly, AWPS has no authority to market or sell hunts; hunters are assigned by the provincial hunting company, and AWPS has no guarantee that their conservation efforts will be rewarded with more business. Secondly, AWPS has no authority to limit the number of hunters arriving, even if a prudent freemarket strategy calls for curtailing harvest in the shortterm to assure a sustainable offtake. Thirdly, AWPS is not in direct control of the receipts from the services it provides; payments are often late and some never arrive at all, and AWPS thus has no power to budget or allocate resources in a way that will assure its own success. Fourthly, AWPS has no control or influence over the quantity or quality of habitat that provides the basis of the wildlife population.

The existence of the motivated and capable AWPS staff provides more potential for conservation than would their absence. Thus, despite its current limitations, we recommend that designation of KIHA as an international hunting area be maintained, because we doubt that national, provincial, area or county governments would provide funding should hunting be terminated.

Alternatively, KIHA could be designated as a nature reserve, but by itself this is unlikely to improve the prognosis for argali. The neighbouring Hashiha'er hunting area in Subei County is included within the Yanchiwan Nature Reserve, but Hashiha'er appears to be managed similarly to KIHA, and is facing similar threats. Nature reserve designation for this portion of Subei County has not limited grazing, mining, poaching or legal trophy hunting, all of which appear to continue at levels similar to those seen in the nominally unprotected KIHA. The difficulty of managing nature reserves where funding is insufficient and economic concerns predominate is not unique to western Gansu or provincial level reserves, but has been documented throughout China and for national-level reserves (WWF, 1998; Liu et al., 2001).

In China the policy of conserving wildlife through a market-based approach will almost certainly continue. On this basis the recommendations that we make here require no additional funding from government sources, and existing funding from international hunters could continue to act as the main financial support. We recommend that: (1) all hunting fees received in-country should be made to AWPS directly, rather than filtered down from various higher-level government units; (2) other government units should be reimbursed by AWPS only for documented expenditures made in support of the hunting programme, allowing AWPS to spend the remaining income on wildlife conservation, habitat protection, and minimizing conflicts with other economic activities in KIHA; (3) exclusive rights to critical wildlife habitats within KIHA should be purchased by AWPS so that argali are prioritized over livestock where necessary, domestic herds should be purchased in key areas, and sold for slaughter or to pastoralists living in less sensitive areas, and those pastoralists bought out by the programme should be assisted in finding new employment; (4) Aksai County should be reimbursed by AWPS for lost tax income resulting from reductions in livestock herds; (5) Frequent patrolling should be initiated to ensure that pastures purchased and reserved for wildlife are not used by domestic livestock or otherwise compromised, and to deter poaching; (6) Biennial population surveys should be initiated (based on the model provided by Harris et al., 2001), and an annual quota of trophy argali rams be set as $2 \%$ of the total number of argali (all sexes and ages; Harris, 1993) counted during the survey; (7) taxes on domestic livestock should be used to discourage pastoralists from keeping large herds of horses. 
Our discussions with AWPS staff indicate that these recommendations would be welcomed and are feasible at their level. Budget projections suggest that the activities listed above could be accomplished with current levels of fees from hunters, if those funds were allocated directly to AWPS. However, these changes would require devolution of authority and release of these fees from higher governmental levels, both of which may be resisted. Some of that resistance is grounded in ignorance of the threats the wildlife faces in Aksai despite the hunting programme, and some of it in distrust of the intentions and abilities of county-level wildlife staff. Our work in Aksai was intended to reduce that ignorance and distrust. An additional barrier, common throughout China, is the reluctance of those at senior levels to empower those at junior levels. We suggest that authorities governing imports of wildlife in the EU, USA, and other regions where trophy hunters live should work with hunting agents to persuade the appropriate authorities in China that reforms to the hunting system are ultimately in the best interests of both wildlife and hunters.

\section{Acknowledgements}

Funding for this work came from the Robert M. Lee Foundation at the University of Montana, the National Geographic Society, the Denver Zoological Foundation, and the Lit Ng Charitable Trust. We thank Wang Wei, Lajiacairen, Huang Jianhua, Ma Chongyu, and Zhang Guilin in China, and J. Franz and V. Burton in Montana for administrative support. Fieldwork was assisted by Ali Abulterp, Mamil Muhat, Chen Hu, Laitip, Dong Yongcun, D. Bedunah, C. Loggers, and L. Metzgar. R. Perrier produced the map. We thank R. Reading and an anonymous reviewer for improvements; an earlier version was improved by suggestions from $\mathrm{D}$. Bedunah, L. Metzgar, and C. Loggers. This work could not have been conducted without the outstanding work of Ali Abulterp, Mamil Muhat, Pei Qianxing, Chen $\mathrm{Hu}$, and others in Aksai - we are grateful for their assistance and friendship. Errors in understanding or interpretation are solely our responsibility.

\section{References}

Aksai County (1985) A brief of Aksai Kazak Autonomous County. Gansu Ethnic Publishing House, China [in Chinese].

Cai, G.Q., Liu, Y.S. \& O'Gara, B.W. (1989) Observations of large mammals in the Qaidam Basin and its peripheral mountainous areas in the People's Republic of China. Canadian Journal of Zoology, 68, 2021-2024.

Carey, J. \& Dehn, M. (1998) Average age of harvest: what is it really telling us? Northern Wild Sheep and Goat Council, 11, 207-215.
Cunha, S.F. (1997) Hunting of rare and endangered fauna in the mountains of post-Soviet Central Asia. In Proceedings of the 8th International Snow Leopard Symposium, (eds R. Jackson \& A. Ashmad), pp. 110-120. International Snow Leopard Trust, Seattle, Washington, DC, USA.

CWCA (1998) China Hunting Program 1998. Unpublished brochure. China Wildlife Conservation Association, Beijing, China.

Freese, C.H. (1997) The 'use it or lose it' debate: issues of a conservation paradox. In Harvesting Wild Species: Implications for Biodiversity Conservation (ed. C.H. Freese), pp. 1-48. Johns Hopkins University Press, Baltimore, USA.

Freese, C.H. (1998) Wild Species as Commodities: Managing Markets and Ecosystems for Sustainability. Island Press, Washington, DC, USA.

Gansu Forestry Bureau (1990) Introduction to the Management Status of Gansu Wildlife and Nature Reserves. Unpublished manuscript, August 28, 1990, Lanzhou, Gansu, China [in Chinese].

Harris, R.B. (1993) Wildlife conservation in Yeniugou, Qinghai province, China. PhD dissertation, University of Montana, USA.

Harris, R.B. (1995) Ecotourism versus trophy hunting: incentives toward conservation in Yeniugou, Tibetan Plateau, China. In Integrating People and Wildlife for a Sustainable Future (eds J.A. Bissonette \& P.R. Krausman), pp. 228-234. The Wildlife Society, Bethesda, Maryland, USA.

Harris, R.B. (1999) Argali hunting area in China: 1999 update. Caprinae: Newsletter of the IUCN Caprinae Specialist Group, December 1999, 3-5.

Harris, R.B. \& Pletscher, D.H. (1997) Strengthening Wildlife Conservation in the Kharteng Valley, Aksai Kazak Autonomous County, Gansu Province, China, with Particular Focus on Incentives to Conservation of Argali (Ovis ammon) through International Hunting. Unpublished report, University of Montana, Missoula, USA.

Harris, R.B. \& Bedunah, D.J. (2001) Sheep vs. Sheep: Argali and Livestock in Western China. Unpublished final report. University of Montana, Missoula, USA.

Harris, R.B., Ali, A. \& Mamil, M. (2001) Large Mammal Survey, Autumn 2000: Aksai International Hunting Area. Unpublished final report. University of Montana, Missoula, USA.

Hilton-Taylor, C. (compiler) (2000) 2000 IUCN Red List of Threatened Species. IUCN, Gland, Switzerland and Cambridge, UK.

Hobbs, N.T. \& Swift, D.M. (1985) Estimates of habitat carrying capacity incorporating explicit nutritional constraints. Journal of Wildlife Management, 49, 814-822.

Horn, H.S. (1966) Measurement of 'overlap' in comparative ecological studies. American Naturalist, 100, 419-424.

Jiang, Z.G. (2000) Trophy Hunting Quota of Caprinae Species in China. Unpublished report, May 2000, Taxonomy Workshop of the IUCN Caprinae Specialists Group, Ankara, Turkey.

Lewis, D.M. \& Alpert, P. (1997) Trophy hunting and wildlife conservation in Zambia. Conservation Biology, 11, 59-68.

Liu, Y.S. (1995) International hunting and the involvement of local people, Dulan, Qinghai, People's Republic of China. In Integrating People and Wildlife for a Sustainable Future (eds J.A. Bissonette \& P.R. Krausman), pp. 63-67. The Wildlife Society, Bethesda, Maryland, USA.

Liu, C.G., Lu, J., Yu, Y.Q., Wang, W., Ji, M.Z. \& Guo, S.T. (2000) A comprehensive evaluation on management of three international hunting grounds for argali in Gansu. Chinese Biodiversity, 8, 441-448 [in Chinese]. 
Liu, J.G., Linderman, M., Ouyang, Z.Y., An, L., Yang, J. \& Zhang, H.M. (2001) Ecological degradation in protected areas: the case of Wolong Nature Reserve for giant pandas. Science, 292, 90-101.

Metcalf, S. (1994) The Zimbabwe communal areas management programme for indigenous resources (CAMPFIRE). In Natural Connections: Perspectives in Community-Based Conservation (eds D. Western, R.M. Wright \& S.C. Strum), pp. 161-192. Island Press, Washington, DC, USA.

PEER (Public Employees for Environmental Responsibility) (1996) Tarnished Trophies: The Department of Interior's Wild Sheep Loophole. Unpublished paper, available from Public Employees for Environmental Responsibility, 2001 S St., NW, Suite 570, Washington, DC 20009-1125, USA.

Schaller, G.B. (1998) Wildlife of the Tibetan Steppe. The University of Chicago Press, Chicago, US.

Stiver, D.K. (1989) An economic valuation of proposed foreign sheep hunts in China. MS thesis, University of Nevada, Reno, USA.

Swanson, T.M. (1992) The role of wildlife utilization and other policies in biodiversity conservation. In Economics for the Wilds: Wildlife, Diversity and Development (eds T.M. Swanson \& E.B. Barbier), pp. 65-102. Island Press, Washington, DC, USA.

Wade, D. (1992) US hunters invited to kill Tibet's rare wildlife. South China Morning Post (Hong Kong), Sept. 1, 1992.
WWF (Worldwide Fund for Nature) (1998) Case Studies of Nature Reserve Strategies. Draft report, Worldwide Fund for Nature, China Programme, Beijing, China. October 1998 [in Chinese].

Yang, Y.Z. (ed.) (1993) Minority Areas in Gansu Province. Gansu Nationalities Press, Lanzhou, Gansu, China [in Chinese].

Zhou, L.H. (ed.) (1990) Qinghai Province Vegetation Map. Science and Technology Press, Beijing, China [in Chinese].

\section{Biographical sketches}

Richard B. Harris is editor-in-chief of Ursus, the annual technical journal of the International Association for Bear Research and Management.

Daniel H. Pletscher is Professor and Director of the Wildlife Biology Program at the University of Montana. He has been active in international conservation for over 20 years, and has conducted numerous studies of ungulates and carnivores. 